\title{
Novel risk genes and mechanisms implicated by exome sequencing of 2,572 individuals with pulmonary arterial hypertension
}

Na Zhu, PhD ${ }^{1,2^{*}}$, Michael W. Pauciulo, MBA ${ }^{3,4^{*}}$, Carrie L. Welch, $\mathrm{PhD}^{1^{*}}$, Katie A. Lutz, BS ${ }^{3}$, Anna W. Coleman, BS ${ }^{3}$, Claudia Gonzaga-Jauregui, $\mathrm{PhD}^{5}$, Jiayao Wang, $\mathrm{MS}^{1,2}$, Joseph M. Grimes ${ }^{1}$, Lisa J. Martin, $\mathrm{PhD}^{3,4}$, Hua He, $\mathrm{MS}^{3}$, PAH Biobank, Yufeng Shen, PhD $2,6^{\star \star}$, Wendy K. Chung, MD, PhD ${ }^{1,7,8^{* *}}$ William C. Nichols, $\mathrm{PhD}^{3,4^{*} \S}$

${ }^{1}$ Department of Pediatrics

Columbia University Medical Center

New York, New York, USA

2Department of Systems Biology,

Columbia University,

New York, New York, USA

${ }^{3}$ Division of Human Genetics

Cincinnati Children's Hospital Medical Center

Cincinnati, $\mathrm{OH}$, USA

${ }^{4}$ Department of Pediatrics

University of Cincinnati College of Medicine

Cincinnati, OH, USA

${ }^{5}$ Regeneron Genetics Center

Regeneron Pharmaceuticals

Tarrytown, New York, USA

${ }^{6}$ Department of Biomedical Informatics

Columbia University,

New York, New York, USA

${ }^{7}$ Herbert Irving Comprehensive Cancer Center

Columbia University Medical Center

New York, New York, USA

${ }^{8}$ Department of Medicine

Columbia University Medical Center

New York, New York, USA

* These authors contributed to the work equally

** These authors supervised the work equally 
$\S$ Corresponding author:

William C. Nichols, PhD.

Division of Human Genetics

Cincinnati Children's Hospital Medical Center

3333 Burnet Avenue MLC 7016

Cincinnati, Ohio

Bill.Nichols@cchmc.org

Total word count: 


\section{Abstract}

Group 1 pulmonary arterial hypertension $(\mathrm{PAH})$ is a rare disease with high mortality despite recent therapeutic advances. Pathogenic remodeling of pulmonary arterioles leads to increased pulmonary pressures, right ventricular hypertrophy and heart failure. Mutations in bone morphogenetic protein receptor type 2 and other risk genes predispose to disease, but the vast majority of non-familial cases remain genetically undefined. To identify new risk genes, we performed exome sequencing in a large cohort from the National Biological Sample and Data Repository for $\mathrm{PAH}$. By statistical association of rare deleterious variants, we found tissue kallikrein 1 and gamma glutamyl carboxylase as new candidate risk genes for idiopathic PAH associated with a later age-of-onset and relatively moderate disease phenotype compared to bone morphogenetic receptor type 2. Both genes play important roles in vascular hemodynamics and inflammation but have not been implicated in PAH previously. These data suggest new genes, pathogenic mechanisms and therapeutic targets for this lethal vasculopathy.

Word count: 154 


\section{Introduction}

Pulmonary arterial hypertension (PAH) is a progressive vascular disease characterized by proliferative remodeling, increased pulmonary pressures and resistance, and high mortality ${ }^{1-4}$. The disease is etiologically heterogeneous, classified as familial (FPAH) as a subset of heritable $\mathrm{PAH}$, idiopathic (IPAH), associated with other medical conditions (APAH, including autoimmune connective tissue disorders (CTD), congenital heart disease (CHD), portopulmonary disease and others), or induced by drugs and toxins (DTOX) ${ }^{5}$. Disease susceptibility includes genetic and environmental factors. Known risk genes underlie $70-80 \%$ of $\mathrm{FPAH}$ and $\sim 10-40 \%$ of IPAH

7. However, the majority of non-familial cases remain genetically undefined.

Heterozygous germline mutations in bone morphogenetic protein receptor type 2 (BMPR2), a member of the transforming growth factor beta (TGF- $\beta$ ) superfamily, are the most common genetic cause of $\mathrm{PAH}{ }^{8-10}$. Similar frequencies of BMPR2 mutations are observed across patient ethnicities and are present in $60-80 \%$ of familial cases ${ }^{11-14}$. BMPR2 mutations are observed in both child- and adult-onset $\mathrm{PAH}{ }^{14}$, and BMPR2 mutation carriers exhibit a younger age-of-onset compared to non-carriers ${ }^{7}$. Mutations in the developmental transcription factor T-box 4 (TBX4) are more common in child-onset $\mathrm{PAH}$, and de novo mutations in many different genes may explain $\sim 19 \%$ of child-onset $\mathrm{PAH}^{14}$. Germline mutations in other genes are individually rare causes of PAH. These include other genes in the TGF- $\beta / B M P$ signaling pathway ${ }^{15}$, hereditary hemorrhagic telangiectasia (HHT) genes activin A receptor type II-like 1 $(A C V R L 1)$ and endoglin $(E N G)^{7}$, eukaryotic initiation translation factor (EIF2AK4) associated with pulmonary veno-occlusive disease (PVOD)/pulmonary capillary hemangiomatosis $(\mathrm{PCH})^{16}$, ${ }^{17}$, caveolin-1 (CAV1) ${ }^{18}$, and channel genes including potassium two pore domain channel $(K C N K 3)^{19}$, ATP-binding cassette subfamily member $8(A B C C 8)^{20}$ and voltage-dependent potassium channel $1.5(\text { KCNA5 })^{21}$.

New risk genes are emerging from large exome- and genome-wide sequencing studies. Rare mutations in SRY-related HMG-box transcription factor (SOX17), a key regulator of 
embryonic vasculogenesis, explain $~ 3.2 \%$ of APAH-CHD ${ }^{22}$, and $0.7 \%$ of IPAH ${ }^{22,23}$. The UK NIHR BioResource - Rare Diseases PAH Study, utilizing 1000 PAH cases of primarily adultonset IPAH, identified an ATPase gene (ATP13A3), growth differentiation factor 2 (GDF2; also known as BMP9) and SOX17 as risk genes contributing to $0.8-1.1 \%$ of cases ${ }^{23}$. The low frequency of risk variants for each gene, except BMPR2, indicates that large numbers of individuals are required for further validation of rare risk genes and pathways, and to understand the natural history of each genetic subtype of PAH.

The National Biological Sample and Data Repository for PAH (AKA PAH Biobank) is a resource of biological specimens as well as clinical and genetic data generated for 2900 group 1 $\mathrm{PAH}$ patients to serve as a resource to the research community to enable larger-scale $\mathrm{PAH}$ studies. Herein, we performed targeted PAH gene and whole exome sequencing of 2572 cases from the PAH Biobank to identify and characterize frequencies and mutations in known PAH risk genes, identify new risk genes, and identify correlations between risk genes and clinical phenotypes.

\section{RESULTS}

\section{Cohort Characteristics}

Characteristics of the PAH Biobank cohort are shown in Table 1 and Supplementary Table 1. The cohort included 2572 cases: 43\% IPAH, 48\% APAH, 4\% FPAH and 5\% other $\mathrm{PAH}$. The APAH cases included 722 associated with autoimmune CTDs (mostly scleroderma with few cases of rheumatoid arthritis, systemic lupus erythematosus and Sjogren's syndrome), 268 with CHD, 139 with portopulmonary disease and 110 with other diseases (HHT, HIV and rare disorders). The "other PAH" group included 110 drug- and toxin-induced (DTOX) PAH, eleven non-familial PVOD/PCH cases and one persistent pulmonary hypertension of the newborn. The majority of cases (91.2\%) were adult-onset with a cohort mean age-of-onset of 48 \pm 19 years (mean \pm SD). However, there was an enrichment of child-onset cases (95/268, 
$37.2 \%, \mathrm{p}<0.0001$ by Chi-square) in the APAH-CHD subclass. As has been reported previously for adult populations ${ }^{24}$, there was an overall 3.7:1 ratio of females to males, with a 9:1 ratio for $\mathrm{PAH}$ associated with autoimmune disease and 1:1.2 ratio for the portopulmonary subclass. The genetic ancestries included European (72\%), Hispanic (12\%), African (11\%), East Asian (2.7\%) and South Asian (1.1\%), fairly equally distributed amongst PAH subclasses. Within the APAH subclass, Africans were more likely to have disease associated with CTD ( $p=0.02)$ and less likely with $\mathrm{CHD}(\mathrm{p}=0.0004)$ or portopulmonary disease $(p=0.001)$, consistent with a previous report ${ }^{25}$. There was an enrichment of portopulmonary disease among patients of Hispanic ancestry $(p=0.02)$.

\section{Rare deleterious variants in established and recently-reported PAH risk genes}

We screened for rare, predicted deleterious variants ((allele frequency $<0.01 \%$ and likely gene damaging (LGD) or missense with REVEL score $>0.5$ (D-Mis), see Methods)) in eleven established PAH risk genes ${ }^{26-29}$ : ACVRL1, BMPR1A, BMPR1B, BMPR2, CAV1, EIF2AK4, ENG, KCNK3, SMAD4, SMAD9, and TBX4 by targeted capture/sequencing, multiple ligationdependent probe amplification (MLPA) (to evaluate deletions/duplications in BMPR2, ACVRL1 and ENG only) and exome sequencing. We also screened the cohort for variants in seven recently-reported risk genes: $A B C C 8, A T P 13 A 3$, GDF2/BMP9, KCNA5, KLF2, SMAD1, and SOX17. Only fourteen percent of cases ( $n=349,22 \%$ IPAH, $12 \%$ APAH, $55 \%$ FPAH, $11 \%$ other) carried rare predicted deleterious variants in these risk genes (Figure 1).

A complete list of cases carrying rare deleterious variants in established risk genes is provided in Supplementary Table 2. Not surprisingly, 68\% of these cases carried variants in BMPR2 ( $\mathrm{n}=119$ variants in 180 cases: $9 \%$ exon deletions, 65\% LGD, 26\% D-Mis). The age-ofonset for BMPR2 variant carriers was $38 \pm 15$ years (mean $\pm S D$ ), significantly younger than that of the whole cohort $(p=1.1 \mathrm{E}-15$, Mann-Whitney $U$ test) but with a wide range of ages from 2 to 76 years (Figure 2). The second most common genetic cause was $T B X 4$, accounting for 
approximately one percent of cases ( $n=23$ cases with 22 variants: 12 LGD, 9 D-Mis and 1 inframe deletion), the majority of whom (57\%) had a diagnosis of IPAH. Although more than $90 \%$ of cases in the PAH Biobank cohort had adult-onset disease, only $48 \%$ of the TBX4 variant carriers had adult-onset disease. The overall mean age-of-onset was $29 \pm 25$ years (Figure 2A), with a bimodal distribution and a significant enrichment of pediatric-onset cases compared to the whole PAH cohort ( $p=6.5 \mathrm{E}-08, \mathrm{RR}=12.3$, binomial test) (Figure $2 \mathrm{~B}$ ), consistent with previous findings ${ }^{14}$. Deleterious variants in nine additional genes were observed: $A C V R L 1(\mathrm{n}=16$ cases, including seven with HHT), SMAD9 (13 cases), CAV1 (10 cases), ENG (6 cases, including two with $\mathrm{HHT}$ ), bi-allelic EIF2AK4 (5 cases, including two with PVOD/PCH), KCNK3 (3 cases), BMPR1A (4 cases), SMAD4 (2 cases), and BMPR1B (2 cases). Four cases (2 IPAH, 2 FPAH) carried risk variants in BMPR2 plus one other risk gene.

A complete list of rare deleterious variants in newly-reported PAH risk genes is provided in Supplementary Table 3. Nearly two-thirds were variants in ABCC8 (26 variants in 29 cases: all D-Mis) or GDF2 (24 variants in 28 cases: 9 LGD, 15 D-Mis). The ABCC8 variants occurred equally in IPAH and APAH cases (50:50) while the GDF2 variants occurred primarily in IPAH cases (75\%). Deleterious variants in the other new PAH risk genes were observed less frequently or not at all: KCNA5 ( $\mathrm{n}=13$ cases), SOX17 (10 cases), ATP13A3 (7 cases), SMAD1 ( 2 cases) and KLF2 ( 0 cases). The mean age-of-onset for these risk gene variant carriers ranged from 41-46 years, with the exception of SOX17 which had a mean age-of-onset of 26 years (Figure 2A), significantly younger than that of the whole cohort $(p<0.003$, Mann-Whitney $U$ test). The female:male ratio among these patients was $4.2: 1$, similar to that of the whole cohort. Overall, $71 \%$ percent of the variants in known risk genes were novel.

Locations of the risk gene variants are shown in Supplementary Figures 1 and 2. For BMPR2, all but two of the D-Mis variants are located within the first 500 amino acids of the protein, mostly within the conserved activin and protein kinase domains (Supplementary Figure 1). While the LGD variants are also clustered within the activin and protein kinase domains, 
twenty-six variants carried by twenty-eight individuals are located downstream of these domains. For the other risk genes, the majority of D-Mis variants are also located in conserved protein domains (Supplementary Figure 2).

\section{Identification of novel PAH risk genes: KLK1 and GGCX}

Our extensive genome screening efforts failed to identify rare deleterious variants in known risk genes for $86 \%$ of the PAH Biobank cases. To identify novel PAH risk genes, we performed a gene-based, case-control association analysis. To prevent confounding by genetic ancestry, we included only participants of European ancestry (cases: $n=1832$; controls: $n=7509$ gnomAD WGS subjects and 5262 unaffected parents from the Pediatric Cardiac Genomics Consortium. To minimize technical batch effects of genotype data between cases and controls, we applied heuristic filters as described in Methods. We observed similar overall frequencies of rare synonymous variants in cases and controls (enrichment rate $=1.01, p$-value $=0.09$ ), a class that is mostly neutral with respect to disease status (Supplemental Table 4). Further, a genelevel burden test confined to rare synonymous variants was consistent with a global null model (Supplementary Figure 3), indicating that technical batch effects would likely have minimal impact on genetic analyses. We then proceeded to test for gene-specific enrichment of rare deleterious variants (allele frequency $<0.01 \%$, LGD and D-Mis) in cases compared to controls. The use of in silico prediction tools to select deleterious missense variants can increase statistical power for rare variant association analyse ${ }^{30}$, but the optimal threshold for deleteriousness scores is often gene-specific ${ }^{31}$. To improve power, we implemented a rare variant burden test utilizing empirically-determined, gene-specific deleterious score thresholds, a "variable threshold test." The association results across all protein-coding genes were generally consistent with the expectation under the null model (Figure 3). Across all PAH subclasses, only two genes exceeded the Bonferoni-corrected threshold for significance: BMPR2 ( $\mathrm{p}=1.0 \mathrm{E}-07, \mathrm{FDR}=0.002)$ and $K L K 1(\mathrm{p}=2.0 \mathrm{E}-07, \mathrm{FDR}=0.002)$ (Figure 3$). K L K 1$ encodes 
kallikrein 1, also known as tissue kallikrein, involved in the regulation of systemic blood pressure and vascular remodeling but not previously associated with pulmonary hypertension ${ }^{32,33}$. Two other known risk genes, $A C V R L 1$ and GDF2, fell just below the cut-off for significance. We next repeated the analysis using 812 IPAH cases only (all European) and observed significant associations for BMPR2 ( $\mathrm{p}=1.0 \mathrm{E}-7, \mathrm{FDR}=9.0 \mathrm{E}-04), K L K 1$ ( $\mathrm{p}=1.0 \mathrm{E}-7, \mathrm{FDR}=9.0 \mathrm{E}-04), \mathrm{GDF} 2$ $(p=3.0 E-07, F D R=0.002)$ and $G G C X(p=5.0 E-07, F D R=0.002)$ (Figure 4). GGCX encodes gamma-glutamyl carboxylase, implicated in coagulation factor deficiencies and ectopic mineralization of soft tissues ${ }^{34}$. These four genes were the only genes to reach genome-wide significance among IPAH cases. IPAH risk gene, TBX4, fell just below the cut-off for significance. All association results for the total cohort or IPAH alone, with $p \leq 0.001$, are listed in Figures 3 and 4, respectively. Analysis of the depth of sequencing coverage of the targeted regions in KLK1 and GGCX indicated that nearly $100 \%$ of samples attained read depths of at least $15 \mathrm{X}$, excluding the possibility that the associations were driven by coverage differences between cases and controls (Supplemental Figure 4).

We next screened the entire PAH Biobank cohort, including participants of nonEuropean ancestry, for rare deleterious variants in KLK1 and GGCX. In total, 12 cases carried $K L K 1$ variants (10 IPAH, $2 \mathrm{APAH}$ ) and 28 cases carried GGCX variants (17 IPAH, 9 APAH, 1 FPAH, 1 unknown subclass) (Table 2). Most of the participants were of European ancestry, however, for GGCX there were also six cases of African and three cases of Hispanic ancestries. The mean age-of-onset was similar to that of the overall cohort for both genes $(K L K 1,49 \pm 6$; GGCX, $49 \pm 3$ ). The variants for KLK1 included four LGD (1 stop-gain, 2 frameshift, 1 splicing) and eight D-Mis; variants for GGCX included six LGD (5 stop-gain, 1 frameshift), twenty-one DMis and one in-frame deletion. Three KLK1 (1 LGD, 2 D-Mis) and five GGCX (1 LGD, 4 D-Mis) variants were recurrent in the cohort. Locations of the variant amino acid residues are shown in 
Figure 5. All but one of the $K L K 1$ and two of the GGCX missense variants, as well as the inframe deletion, occur in conserved enzymatic domains.

$K L K 1$ belongs to a contiguous gene family cluster on chromosome 19 encoding fifteen distinct peptidases. While some have highly restricted expression patterns (ie $K L K 2$ and $K L K 3$ in prostate), others are widely expressed ${ }^{35}$. Nine of the family members, including $K L K 1$, are expressed in lung and have been implicated in various lung diseases - inflammatory respiratory diseases, viral infections, and cancers ${ }^{36}$. We tested for enrichment of rare deleterious variants in the gene-set expressed in lung and observed a significant enrichment of LGD+D-Mis variants in European cases compared to controls (enrichment rate $=2.1, p=0.004$ ) (Supplementary Table 5A). We then performed gene-specific association analyses to determine which genes were contributing to the enrichment. The associations were stronger for IPAH than all PAH; while $K L K 1$ was the only gene to exceed the Bonferroni-corrected threshold for significance (OR=13.9, $p=2.00 \mathrm{E}-07$ for all $\mathrm{PAH} ; \mathrm{OR}=26.2, \mathrm{p}=1.00 \mathrm{E}-07$ for IPAH), five additional family members had an enrichment rate of rare deleterious variants greater than 2.0 for IPAH (Supplementary Table 5B).

\section{Clinical phenotypes of $K L K 1$ and GGCX variant carriers}

Hemodynamic measurements at the time of $\mathrm{PAH}$ diagnosis for individual carriers of KLK1 and GGCX variants are provided in Table 3. Clinical phenotypes of IPAH participants with $K L K 1$ or GGCX variants did not differ from that of other IPAH cases without variants in known risk genes (Supplementary Table 6). Overall, participants with predicted deleterious variants in either gene exhibited less severe clinical phenotypes compared to participants with variants in BMPR2. Carriers of both $K L K 1$ and GGCX variants were older at PAH onset and had decreased mean pulmonary arterial pressure, increased cardiac output and decreased pulmonary vascular resistance compared to BMPR2 carriers (Table 3). Furthermore, both KLK1 and GGCX carriers 
had increased ratios of mean (systemic) arterial pressure to mean pulmonary artery pressure compared to BMPR2 carriers (MAP:MPAP, Table 3).

A known $K L K 1$ single nucleotide polymorphism conferring at least partial loss of function occurs with high frequency in the general population ${ }^{37,38}$. The c.230G>A;p.R77H SNP (formerly called c.230G>A;p.R53H) has been associated with decreased urinary kallikrein activity and aberrant flow-mediated arterial remodeling but not systemic hypertension ${ }^{37,38}$. We screened the PAH Biobank cohort for the c.230G>A;p.R77H SNP and compared the cohort allele frequency with the frequency observed in gnomAD. No enrichment was observed in the PAH Biobank cohort (Supplementary Table 7), and none of the carriers of rare deleterious $K L K 1$ variants also carried the c.230G>A;p.R77H SNP. Thus, the observed association of rare, deleterious $K L K 1$ variants with $\mathrm{PAH}$ and associated phenotypes could not be explained by coincident occurrence of the common SNP.

\section{DISCUSSION}

Using exome sequencing of a large PAH Biobank cohort recruited by 28 participating centers, followed by rare deleterious variant identification and gene-based association analysis, we identified $K L K 1$ and $G G C X$ as novel candidate genes for $\mathrm{PAH}$. These candidate risk genes suggest new pathogenic mechanisms outside of the TGF- $\beta$ /BMPR2 signaling pathway. We showed that carriers of rare, predicted deleterious variants in $K L K 1$ or GGCX have less severe clinical phenotypes compared to carriers of BMPR2 variants. In addition, we identified 252 novel rare deleterious variants in seventeen known $\mathrm{PAH}$ risk genes and confirmed the importance of TBX4 and SOX17 in early-onset disease as well as the genome-wide association of GDF2 with IPAH.

The results of our study replicate some, but not all, of the recently-reported findings from the UK NIHR BioResource - Rare Diseases PAH Study. Similar to that cohort ${ }^{23}$, GDF2 reached significant genome-wide association among 812 IPAH cases of European ancestry in the PAH 
Biobank; with additional variants observed in a small number of APAH and FPAH participants. In total, we identified twenty-four variants, only two of which had been reported previously. GDF2 encodes a well-characterized ligand for BMPR2, and these data further confirm an important role for GDF2 in IPAH, as well as other PAH subclasses. Similar to the UK cohort, as well as our previous report of a cohort enriched in APAH-CHD cases $^{22}$, we observed a low frequency of SOX17 variants $(0.4 \%)$ in the PAH Biobank likely due, at least in part, to the paucity of APAH-CHD cases in both Biobank cohorts. Interestingly, a genome-wide association study of common SNPs involving both the PAH Biobank and the UK NIHR BioResource - Rare Diseases PAH Study identified SNPs in a putative endothelial-acting enhancer region of SOX17 in $\mathrm{PAH}^{39}$, suggesting that common variants may play an important role in susceptibility to $\mathrm{PAH}$. Neither ATP13A3 nor AQP1 reached genome-wide significance in our study. We analyzed $A T P 13 A 1$ rare deleterious variants and identified seven cases with novel variants. $A Q 1$ not only failed to reach genome-wide significance but also was not among the expanded list of genes with $\mathrm{p} \leq 0.001$ for either the whole $\mathrm{PAH}$ cohort or IPAH alone. Based on the small relative risks and associated confidence intervals from the UK NIHR BioResource - Rare Diseases PAH Study (RR=0.37, Cl: 0.06-1.47 for $A T P 13 A 3$; $\mathrm{RR}=0.19, \mathrm{Cl}: 0.004-1.53$ for $A Q P 1)$, it was not unexpected that that by chance we would observe no association with these genes and PAH.

The new PAH candidate risk genes identified in the current study, KLK1 and GGCX, are both expressed in lung and vascular tissues, play important roles in vascular hemodynamics and inflammation, but have not been implicated in $\mathrm{PAH}$ previously. $K L K 1$, also known as tissue kallikrein 1 , is a major component of the kallikrein-kinin system that, together with the reninangiotensin system, regulates blood pressure and cardiovascular function. In rodent and in vitro studies, $K L K 1$ is constitutively expressed by endothelial cells, and endothelial activation leads to release of active protease, matrix degradation, smooth muscle cell migration and vascular sprouting $^{32}$, processes relevant to $\mathrm{PAH}$. Gene delivery of tissue $K L K 1$ via adenoviral vectors, 
protein infusion or genetically-modified stem cells has shown beneficial effects in multiple models of vascular diseases ${ }^{40} . K L K 1$ is part of a highly-conserved, serine protease subfamily. We observed enrichment of rare deleterious variants in a gene-set of nine $K L K$ genes expressed in lung, suggesting candidate genes for further investigation including $K L K 12$ which may play a role in angiogenesis via indirect regulation of vascular endothelial growth factor ${ }^{41}$. The potential for gene delivery of $K L K s$ as a treatment for $\mathrm{PAH}$ should prioritize this gene family for functional studies.

GGCX encodes gamma glutamyl carboxylase, responsible for the post-translational modification of vitamin- $\mathrm{K}$ dependent proteins involved in coagulation, soft tissue mineralization, inflammation, bone formation and cell proliferation ${ }^{34}$. Homozygous mutations in GGCX cause vitamin K-dependent clotting factor deficiency (MIM \#277450) as well as pseudoxanthoma elasticum (MIM \#264800), an ectopic mineralization disorder. None of the PAH Biobank GGCX heterozygous variant carriers had diagnoses of bleeding disorders or pseudoxanthoma elasticum. $G g c x^{-/}$mice die pre- or perinatally due to massive bleeding but heterozygotes are viable $^{42}$. Thus, the heterozygous knock-out mouse may provide a model for testing the effect of Ggcx on PAH phenotypes.

The differences in etiology, clinical course and prognosis for child- vs adult-onset PAH is an area of active investigation. Previous studies have implicated BMPR2, TBX4 and SOX17 in child-onset disease. In our large PAH Biobank cohort, BMPR2 variant carriers exhibited a shift towards younger age-of onset, but the overall age distribution was similar to that of the whole cohort. TBX4 exhibited a bi-modal distribution with significant enrichment of variants among pediatric-onset cases. Consistent with our previous report of SOX17 in APAH-CHD, SOX17 carriers in the PAH Biobank also had a relatively young mean age-of-onset (26 y). The hypothesis that pediatric $\mathrm{PAH}$ is linked to lung growth and development ${ }^{43}$ is consistent with roles for TBX4 and SOX17, prominent developmental transcription factors ${ }^{44}$, in early-onset disease. 
In summary, we have identified $K L K 1$ and GGCX as new candidate risk genes for $\mathrm{PAH}$, accounting for $\sim 0.4 \%$ and $0.9 \%$ of $\mathrm{PAH}$ Biobank cases, respectively. These genes require further genetic validation and functional assessment with the goal of providing new therapeutics for this lethal vasculopathy. The growing list of PAH risk genes and variants indicate that exome sequencing may be useful in families with $\mathrm{PAH}$ if no genetic cause is identified with panel gene testing. Furthermore, genomic studies of larger international consortia will be necessary to better clinically characterize these rare genetic subtypes of $\mathrm{PAH}$.

\section{METHODS}

\section{Participants}

The PAH Biobank is housed and maintained at the Cincinnati Children's Hospital Medical Center (CCHMC). Thirty-eight North American PH Centers participate in the PAH Biobank to identify and enroll patients meeting eligibility criteria. Each enrolling center also completes an electronic case report form with clinical data for each patient enrolled. Participants are diagnosed according to the World Health Organization $\mathrm{PH}$ group I classification ${ }^{5}$ and the diagnosis of PAH is confirmed by medical record review including right heart catheterization. The cohort for this genetic analysis included 2534 singletons, 19 duos (proband and one unaffected parent) and 19 trios (proband and two unaffected biological parents). Written informed consent (and assent when appropriate) was obtained from participants or parents/legal guardians under a protocol approved by the institutional review board at CCHMC as well as those at each of the participating PH Centers. Written informed consent for publication was obtained at enrollment. The data and resources are made available to the research community for hypothesis-driven projects via an application process (www.pahbiobank.org). A subset including 183 affected participants were included in previous publications from our group ${ }^{14,20,22 .}$

\section{Targeted sequencing and multiplex ligation-dependent probe amplification (MLPA)}


After proper informed consent, blood samples were collected and shipped to CCHMC for processing and generation of genetic data including panel sequencing of up to twelve genes, SNP genotyping using the Illumina OMNI5-4 Beadchip and limited MLPA dosage data. Targeted Next-Generation sequencing was performed with 250 ng DNA using the Illumina Tru-seq Custom Amplicon system (Illumina, USA) according to manufacturer's instructions. Custom amplicons were designed with Illumina's DesignStudio for the coding sequence of BMPR2, ACVRL1, ENG, CAV1, SMAD9, KCNK3, and EIF2AK4, for which all participants were sequenced. $A B C C 8, G D F 2, K C N A 5, S M A D 4$, and TBX4 were added to the panel later and a subset of 739 were also sequenced for these genes. Each sample was sequenced using the Illumina MiSeq® instrument with paired-end 250 nucleotide read lengths. Demultiplexing, base calling and alignment were executed using the default Illumina TruSeq Amplicon Workflow. Fastq files were aligned and visualized with NextGENe (SoftGenetics, USA). Variants were confirmed via Sanger sequencing on an ABI 3730xI DNA analyzer (Applied Biosystems, USA).

MLPA was performed with $100 \mathrm{ng}$ of genomic DNA according to manufacturer's instructions using the P093 Salsa MLPA probe sets (MRC-Holland, Amsterdam, The Netherlands). This probe set includes probes for all exons of BMPR2, ALK1, and ENG. Probe amplification products were run on an ABI 3730xI DNA Analyzer using GS500 size standard (Applied Biosystems). MLPA peak data was imported into Coffalyser (MRC-Holland) for quality checks and dosage ratio analysis. A dosage ratio value of $\leq 0.7$ was used as the boundary for deletions, and $\geq 1.35$ was used as the boundary for duplications.

\section{Whole exome sequencing (WES)}

Exome sequencing was performed for the entire cohort in collaboration with the Regeneron Genetics Center (RGC). In brief, genomic DNA was prepared with a customized reagent kit from Kapa Biosystems and captured using Integrated DNA Technologies xGen lockdown probes. All samples were sequenced on the Illumina HiSeq 2500 platform using v4 chemistry, generating 
76 bp paired-end reads. At least $90 \%$ of targeted regions have read depth coverage $\geq 15 x$ for all exome sequencing samples.

\section{WES Data analysis}

We used a previously established bioinformatics procedure ${ }^{45}$ to process and analyze exome sequence data. Specifically, we used BWA-MEM (Burrows-Wheeler Aligner) ${ }^{46}$ to map and align paired-end reads to the human reference genome (version GRCh38/hg18), Picard MarkDuplicates to identify and flag PCR duplicate reads and GATK HaplotypeCaller (version $3.5)^{47,48}$ to call genetic variants. We used heuristic filters to minimize technical artifacts, excluding variants that met any of the following criteria: missingness $>10 \%$, minimum read depth $\leq 8$ reads, allele balance $\leq 25 \%{ }^{49}$, and genotype quality $<90$. We obtained gnomAD whole genome sequence (WGS) as part of the control set. Only variants with FILTER "PASS" in gnomAD WGS (data release v 2.02) and restricted to the $x$ Gen captured protein coding region were included in the analysis. We used $\mathrm{ANNOVAR}^{50}$ to annotate the variants and aggregate information about allele frequencies $(\mathrm{AF})$ and in silico predictions of deleteriousness. Rare variants were defined as $\mathrm{AF} \leq 0.01 \%$ in both ExAC and gnomAD WES datasets. An exception was made for recessive inheritance of EIF2AK4 variants, in which the AF cut-off was $\leq 1 \%$ Deleterious variants were defined as likely-gene-disrupting (including premature stop-gain, frameshift indels, canonical splicing variants and exon deletions) or predicted damaging missense with REVEL score $>0.5$ (D-Mis), as previously described ${ }^{22,51}$. Insertion/deletion variants were manually inspected using Integrative Genome Viewer (IGV). All variants in known $\mathrm{PAH}$ risk genes, included in Supplementary Tables 2 and 3, are deposited in ClinVar (pending).

\section{Statistical analysis}


To identify novel candidate risk genes, we performed a gene-based case-control association test comparing the frequency of rare deleterious variants in $\mathrm{PAH}$ cases with population controls. The controls consisted of gnomAD WGS subjects as well unaffected parents from the Pediatric Cardiac Genomics Consortium (PCGC) ("internal controls”) ${ }^{45}$ to increase statistical power. To control for confounding from genetic ancestry, we selected 1832 cases and 5262 internal controls of European ancestry using principle components analysis implemented in PLINK version $1.9^{52}$, and 7509 non-Finnish, European (NFE) gnomAD subjects. Relatedness was checked using Peddy ${ }^{52}$, and only unrelated cases were included in the association test. To guard against batch effects in combined datasets from different sources ${ }^{53}$, we applied heuristic filters including restriction of investigated regions to the intersection of regions captured by xGen, NimbleGen and MedExome; regions uniquely mapping to the reference sequence; regions with at least $10 \mathrm{X}$ coverage in $90 \%$ of samples; and excluding regions of low complexity. Variant filters included genotype quality $>60$, and removal of variants with allele fraction $<0.25$, alternate allele depth $<4$ or total read depth $<10$. We then tested for similarity of the rare synonymous variant rate among cases and controls.

The analysis of disease-associated genes was confined to gene-specific enrichment of rare, deleterious variants (AF $\leq 0.01 \%$, LGD or D-mis). We used REVEL scores to predict the deleteriousness of missense variants. Instead of using a REVEL score threshold of 0.5 based on genome-wide variants ${ }^{51}$, we adapted a gene-specific variable threshold test ${ }^{54}$. We performed binomial tests with variable REVEL score cut-offs ranging from 0.2-1 with 0.05 intervals, for each gene, and determined a cut-off is optimal if it achieves the smallest p-value $\left(\boldsymbol{P}_{\mathbf{0}}\right)$. Then we perform 10,000,000 permutations (shuffling of case-control label of rare genotypes); in each permutation, we obtained the smallest $p$-value $\left(\boldsymbol{P}^{\prime}\right)$ by the same variable REVEL threshold procedure. We define the empirical $p$-value of the gene as the fraction of permutations where $\boldsymbol{P}^{\boldsymbol{\prime}}$ is equal or smaller than $\boldsymbol{P}_{\mathbf{0}}$. We set REVEL score of LGD variants to 1 
(more severe). In each binomial test, we assumed that under the null model, the number of rare deleterious variants observed in cases should follow a binomial distribution, given the total number of such variants in cases and controls, and a rate determined by fraction of cases in total number of subjects (cases and controls). We use binom.test function in R to calculate $p$ values in binomial tests. We defined the threshold for genome-wide significance by Bonferroni correction for multiple testing ( $n=20,000$ genes, threshold $p$-value $=2.5 e-6)$. We used the Benjamini-Hochberg procedure to estimate false discovery rate (FDR) by p.adjust in R. All GGCX and KLK1 variants reported herein were confirmed by Sanger sequencing.

\section{References}

1. Vonk-Noordegraaf, A. et al. Right heart adaptation to pulmonary arterial hypertension: physiology and pathobiology. J. Am. Coll. Cardiol. 62, D22-33 (2013).

2. Ryan, J.J. \& Archer, S.L. The right ventricle in pulmonary arterial hypertension: disorders of metabolism, angiogenesis and adrenergic signaling in right ventricular failure. Circ. Res. 115, 176-188 (2014).

3. Humbert, M. et al. Survival in patients with idiopathic, familial, and anorexigenassociated pulmonary arterial hypertension in the modern management era. Circulation 122, 156-163 (2010).

4. Benza, R.L. et al. An evaluation of long-term survival from time of diagnosis in pulmonary arterial hypertension from the REVEAL Registry. Chest 142, 448-456 (2012).

5. Simonneau, G. et al. Haemodynamic definitions and updated clinical classification of pulmonary hypertension. Eur. Respir. J. (2018).

6. Ma, L. \& Chung, W.K. The role of genetics in pulmonary arterial hypertension. J. Pathol. 241, 273-280 (2017).

7. Morrell, N.W. et al. Genetics and genomics of pulmonary arterial hypertension. Eur. Respir. J. (2018).

8. International, P.P.H.C. et al. Heterozygous germline mutations in BMPR2, encoding a TGF-beta receptor, cause familial primary pulmonary hypertension. Nat. Genet. 26, 8184 (2000).

9. Deng, Z. et al. Familial primary pulmonary hypertension (gene PPH1) is caused by mutations in the bone morphogenetic protein receptor-II gene. Am. J. Hum. Genet. 67, 737-744 (2000).

10. Machado, R.D. et al. BMPR2 haploinsufficiency as the inherited molecular mechanism for primary pulmonary hypertension. Am. J. Hum. Genet. 68, 92-102 (2001).

11. Morisaki, H. et al. BMPR2 mutations found in Japanese patients with familial and sporadic primary pulmonary hypertension. Hum. Mutat. 23, 632 (2004). 
12. Kabata, H. et al. Bone morphogenetic protein receptor type 2 mutations, clinical phenotypes and outcomes of Japanese patients with sporadic or familial pulmonary hypertension. Respirology 18, 1076-1082 (2013).

13. Evans, J.D. et al. BMPR2 mutations and survival in pulmonary arterial hypertension: an individual participant data meta-analysis. Lancet Respir. Med. 4, 129-137 (2016).

14. Zhu, N. et al. Exome Sequencing in Children With Pulmonary Arterial Hypertension Demonstrates Differences Compared With Adults. Circ. Genom. Prec. Med. 11, e001887 (2018).

15. Machado, R.D. et al. Pulmonary Arterial Hypertension: A Current Perspective on Established and Emerging Molecular Genetic Defects. Hum Mutat 36, 1113-1127 (2015).

16. Best, D.H. et al. EIF2AK4 mutations in pulmonary capillary hemangiomatosis. Chest 145, 231-236 (2014).

17. Eyries, M. et al. EIF2AK4 mutations cause pulmonary veno-occlusive disease, a recessive form of pulmonary hypertension. Nat. Genet. 46, 65-69 (2014).

18. Austin, E.D. et al. Whole exome sequencing to identify a novel gene (caveolin-1) associated with human pulmonary arterial hypertension. Circ. Cardiovasc. Genet. 5, 336343 (2012).

19. Ma, L. et al. A novel channelopathy in pulmonary arterial hypertension. N. Engl. J. Med. 369, 351-361 (2013).

20. Bohnen, M.S. et al. Loss-of-Function ABCC8 Mutations in Pulmonary Arterial Hypertension. Circ. Genom. Prec. Med. 11, e002087 (2018).

21. Mondejar-Parreno, G. et al. miR-1 is increased in pulmonary hypertension and downregulates Kv1.5 channels in rat pulmonary arteries. J. Physiol. (2018).

22. Zhu, N. et al. Rare variants in SOX17 are associated with pulmonary arterial hypertension with congenital heart disease. Genome Med. 10, 56 (2018).

23. Graf, S. et al. Identification of rare sequence variation underlying heritable pulmonary arterial hypertension. Nat. Comm. 9, 1416 (2018).

24. Batton, K.A. et al. Sex differences in pulmonary arterial hypertension: role of infection and autoimmunity in the pathogenesis of disease. Biol. Sex Differ. 9, 15 (2018).

25. Al-Naamani, N. et al. Racial and ethnic differences in pulmonary arterial hypertension. Pulm. Circ. 7, 793-796 (2017).

26. Best, D.H., Austin, E.D., Chung, W.K. \& Elliott, C.G. Genetics of pulmonary hypertension. Curr. Opin. Cardiol. 29, 520-527 (2014).

27. Chida, A. et al. Missense mutations of the BMPR1B (ALK6) gene in childhood idiopathic pulmonary arterial hypertension. Circ. J. 76, 1501-1508 (2012).

28. Nasim, M.T. et al. Molecular genetic characterization of SMAD signaling molecules in pulmonary arterial hypertension. Hum. Mut. 32, 1385-1389 (2011).

29. Kerstjens-Frederikse, W.S. et al. TBX4 mutations (small patella syndrome) are associated with childhood-onset pulmonary arterial hypertension. J. Med. Genet. 50, 500-506 (2013).

30. Zuk, O. et al. Searching for missing heritability: designing rare variant association studies. Proc. Natl. Acad. Sci. U S A 111, E455-464 (2014).

31. Wilfert, A.B. et al. Genome-wide significance testing of variation from single case exomes. Nat. Genet. 48, 1455-1461 (2016). 
32. Madeddu, P., Emanueli, C. \& El-Dahr, S. Mechanisms of disease: the tissue kallikreinkinin system in hypertension and vascular remodeling. Nat. Clin. Pract. Nephrol. 3, 208221 (2007).

33. Meneton, P. et al. Cardiovascular abnormalities with normal blood pressure in tissue kallikrein-deficient mice. Proc. Natl. Acad. Sci. U S A 98, 2634-2639 (2001).

34. De Vilder, E.Y., Debacker, J. \& Vanakker, O.M. GGCX-Associated Phenotypes: An Overview in Search of Genotype-Phenotype Correlations. Int. J. Mol. Sci. 18 (2017).

35. Shaw, J.L. \& Diamandis, E.P. Distribution of 15 human kallikreins in tissues and biological fluids. Clin. Chem. 53, 1423-1432 (2007).

36. Lenga Ma Bonda, W., lochmann, S., Magnen, M., Courty, Y. \& Reverdiau, P. Kallikreinrelated peptidases in lung diseases. Biol. Chem. 399, 959-971 (2018).

37. Slim, R. et al. Loss-of-function polymorphism of the human kallikrein gene with reduced urinary kallikrein activity. J. Am. Soc. Nephrol. 13, 968-976 (2002).

38. Azizi, M. et al. Arterial and renal consequences of partial genetic deficiency in tissue kallikrein activity in humans. J. Clin. Invest. 115, 780-787 (2005).

39. Rhodes, C.J. et al. Genetic determinants of risk in pulmonary arterial hypertension: international genome-wide association studies and meta-analysis. Lancet Respir. Med. (2018).

40. Devetzi, M. et al. Geneticallymodified stem cells in treatment of human diseases: Tissue kallikrein (KLK1)based targeted therapy (Review). Int. J. Mol. Med. 41, 1177-1186 (2018).

41. Guillon-Munos, A. et al. Kallikrein-related peptidase 12 hydrolyzes matricellular proteins of the CCN family and modifies interactions of CCN1 and CCN5 with growth factors. $J$ Biol. Chem. 286, 25505-25518 (2011).

42. Zhu, A. et al. Fatal hemorrhage in mice lacking gamma-glutamyl carboxylase. Blood 109, 5270-5275 (2007).

43. Abman, S.H. et al. Pediatric Pulmonary Hypertension: Guidelines From the American Heart Association and American Thoracic Society. Circulation 132, 2037-2099 (2015).

44. Karolak, J.A. et al. Complex Compound Inheritance of Lethal Lung Developmental Disorders due to Disruption of the TBX-FGF Pathway. Am. J. Hum. Genet. (2019).

45. Homsy, J. et al. De novo mutations in congenital heart disease with neurodevelopmental and other congenital anomalies. Science 350, 1262-1266 (2015).

46. Li, H., Ruan, J. \& Durbin, R. Mapping short DNA sequencing reads and calling variants using mapping quality scores. Genome Res. 18, 1851-1858 (2008).

47. DePristo, M.A. et al. A framework for variation discovery and genotyping using nextgeneration DNA sequencing data. Nat. Genet. 43, 491-498 (2011).

48. Van der Auwera, G.A. et al. From FastQ data to high confidence variant calls: the Genome Analysis Toolkit best practices pipeline. Curr. Protoc. Bioinformatics 43, 1110 11-33 (2013).

49. Krumm, N. et al. Excess of rare, inherited truncating mutations in autism. Nat. Genet. 47, 582-588 (2015).

50. Wang, K., Li, M. \& Hakonarson, H. ANNOVAR: functional annotation of genetic variants from high-throughput sequencing data. Nucleic Acids Res. 38, e164 (2010).

51. Ioannidis, N.M. et al. REVEL: An Ensemble Method for Predicting the Pathogenicity of Rare Missense Variants. Am. J. Hum. Genet. 99, 877-885 (2016). 
52. Pedersen, B.S. \& Quinlan, A.R. Who's Who? Detecting and Resolving Sample Anomalies in Human DNA Sequencing Studies with Peddy. Am. J. Hum. Genet. 100, 406-413 (2017).

53. Tom, J.A. et al. Identifying and mitigating batch effects in whole genome sequencing data. BMC Bioinformatics 18, 351 (2017).

54. Price, A.L. et al. Pooled association tests for rare variants in exon-resequencing studies. Am. J. Hum. Genet. 86, 832-838 (2010).

\section{Acknowledgements}

Samples and/or data from the National Biological Sample and Data Repository for PAH, which receives government support under an investigator-initiated grant (R24 HL105333 to WCN) awarded by the National Heart Lung and Blood Institute (NHLBI), were used in this study. We thank contributors, including the Pulmonary Hypertension Centers who collected samples used in this study, as well as patients and their families, whose help and participation made this work possible. Exome sequencing and genotyping data were generated by the Regeneron Genetics Center. Other funding support was provided by NHLBI HL060056 (WKC) and NIH R01GM120609 (YS).

\section{Authors' contributions}

MWP, WCN, WKC conceived and designed the study. WCN, MWP, WKC, LJM, HH, NZ, YS, JW analyzed and interpreted the data. WCN, MWP, CLW, NA, WKC, YS wrote the manuscript. KL, MWP, CW, JG, CLW, AWC, PAH Biobank collected patient samples and/or clinical information. CG-J provided and analyzed WES. All authors contributed and discussed the results and critically reviewed the manuscript.

\section{Competing Interests}

CG-J is a full time employee of the Regeneron Genetics Center from Regeneron Pharmaceuticals Inc. and receives stock options as part of compensation. The remaining authors declare that they have no competing interests. 


\section{Figure Legends}

Figure 1. Contribution of known PAH risk genes in the PAH Biobank cohort $(n=2572$

cases). BMPR2, ACVRL1/ENG, TBX4; Other established risk genes included in the analysis: BMPR1A, BMPR1B, CAV1, EIF2AK4, KCNK3, SMAD4 and SMAD9; Newly validated risk genes: ABCC8, ATP13A1, GDF2, KCN5A, KLF2, SMAD1 and SOX17.

Figure 2. Age-of-disease onset for PAH Biobank cases with rare deleterious variants in known PAH risk genes. a) Box plots showing median, interquartile range and $\mathrm{min} / \mathrm{max}$ values for age-of-disease onset (i.e. age at diagnostic right heart catheterization). The number of cases carrying variants for each gene is given above each box plot. Genes represented by less than four cases are not shown. b) Histogram plots showing age-of-onset distributions for the whole cohort $(n=2572)$, BMPR2 $(n=180)$ or TBX4 $(n=23)$ variant carriers. Red vertical lines indicate the group means. BMPR2 carriers had a younger mean age-of-onset (mean=37 y, SD=15; MannWhitney $U$ test: $p=1.1 E-15$ ) but no enrichment of child-onset cases (binomial test: $p=1$, $\mathrm{RR}=0.93$ ) compared to the whole cohort, whereas $T B X 4$ carriers had a younger mean age-ofonset (mean=29 y, SD=25; Mann-Whitney $U$ test: $p=0.001$ ) and significant enrichment of childonset cases (binomial test: $p=6.5 E-08, R R=12.3$ ) compared to the whole cohort.

Figure 3. Gene-based association analysis using 1,832 European cases from all PAH subclasses and 12,771 European controls. a) Results of a binomial test confined to rare LGD and D-Mis (REVEL variable threshold) variants in 20,000 protein-coding genes. Horizontal gray line indicates the Bonferroni-corrected threshold for significance. b) Complete list of top association genes $(p<=0.001)$.

Figure 4. Gene-based association analysis using 812 European IPAH cases and 12,771 European controls. a) Results of a binomial test confined to rare LGD and D-Mis (REVEL variable threshold) variants in 20,000 protein-coding genes. Horizontal gray line indicates the Bonferroni-corrected threshold for significance. b) Complete list of top association genes $(p<=0.001)$. 
Figure 5. Locations of rare, predicted deleterious variants in $K L K 1$ (a) and GGCX (b) across the PAH Biobank cohort ( $\mathrm{n}=\mathbf{2 5 7 2}$ cases). Locations are provided within the twodimensional protein structures. The numbers of variants at each amino acid position are indicated along the y-axes. The vertical gray lines indicate exon borders. D-MIS, predicted damaging missense; LGD, likely-gene-disrupting (stopgain, frameshift, splicing). 
Table 1. PAH Biobank cohort demographic and hemodynamic data.

\begin{tabular}{|c|c|c|c|c|c|}
\hline & ALL & IPAH & APAH & FPAH & Other* \\
\hline Total (\%) & 2572 & $1110(43.2)$ & $1239(48.2)$ & $101(3.9)$ & $122(4.7)$ \\
\hline \multicolumn{6}{|l|}{ Age-of-onset, n (\%) } \\
\hline Child (dx age <19) & $226(8.8)$ & $94(8.5)$ & $112(9.0)$ & $15(14.9)$ & $5(4.1)$ \\
\hline Adult (dx age $>=19$ ) & 2345 (91.2) & $1015(91.4)$ & $1127(91.0)$ & $86(85.1)$ & $117(95.9)$ \\
\hline Mean age & $48 \pm 19$ & $48 \pm 18$ & $49 \pm 19$ & $37 \pm 15$ & $47 \pm 15$ \\
\hline \multicolumn{6}{|l|}{ Gender, n (\%) } \\
\hline Female & $2023(78.7)$ & $868(78.2)$ & $996(80.4)$ & $69(68.3)$ & $90(73.8)$ \\
\hline Male & $549(21.3)$ & $242(21.8)$ & $243(19.6)$ & $32(31.7)$ & $32(26.2)$ \\
\hline Female:male ratio & $3.7: 1$ & $3.6: 1$ & $4.1: 1$ & $2.2: 1$ & $2.8: 1$ \\
\hline \multicolumn{6}{|l|}{ Ancestry, n (\%) } \\
\hline European & $1852(72)$ & $809(73.0)$ & $855(69.0)$ & $89(88.1)$ & $99(81.2)$ \\
\hline Hispanic & $315(12.3)$ & $137(12.3)$ & $156(12.6)$ & $10(9.9)$ & $12(9.8)$ \\
\hline African & $292(11.4)$ & $117(10.5)$ & $168(13.6)$ & $1(1)$ & $6(4.9)$ \\
\hline East Asian & $70(2.7)$ & $25(2.2)$ & $41(3.3)$ & 0 & $4(3.3)$ \\
\hline South Asian & $28(1.1)$ & $12(1.1)$ & $15(1.2)$ & $1(1)$ & 0 \\
\hline Others & $15(0.58)$ & $10(0.9)$ & $4(0.3)$ & 0 & $1(0.8)$ \\
\hline \multicolumn{6}{|c|}{ Hemodynamic parameters } \\
\hline MPAP $(\mathrm{mmHg})$ & $50 \pm 14$ & $52 \pm 14$ & $48 \pm 14$ & $58 \pm 14$ & $52 \pm 13$ \\
\hline MPCW (mmHg) & $10 \pm 4$ & $10 \pm 4$ & $10 \pm 4$ & $10 \pm 4$ & $11 \pm 4$ \\
\hline CO, Fick (L/min) & $4.5 \pm 1.8$ & $4.5 \pm 1.7$ & $4.6 \pm 1.9$ & $3.6 \pm 1.0$ & $4.2 \pm 1.3$ \\
\hline PVR (Woods units) & $10.7 \pm 7.0$ & $11.2 \pm 7.0$ & $10.0 \pm 7.1$ & $14.9 \pm 6.3$ & $11.0 \pm 6.6$ \\
\hline MAP $(\mathrm{mmHg})$ & $90 \pm 19$ & $91 \pm 20$ & $90 \pm 19$ & $88 \pm 16$ & $94 \pm 19$ \\
\hline MAP:MPAP & $1.9 \pm 0.7$ & $1.9 \pm 0.7$ & $2.0 \pm 0.7$ & $1.6 \pm 0.5$ & $1.9 \pm 0.5$ \\
\hline
\end{tabular}

${ }^{*}$ Other included 110 diet- and toxin-induced PAH, 11 non-familial pulmonary veno-occlusive disease/ pulmonary capillary hemangiomatosis and one persistent pulmonary hypertension of the newborn.

Abbreviations: MPAP, mean pulmonary arterial pressure; MPCW, mean pulmonary capillary wedge pressure; $\mathrm{CO}$, cardiac output by Frick method; PVR, pulmonary vascular resistance; MAP, mean arterial pressure. 
Table 2. Rare, predicted deleterious $K L K 1$ and GGCX variants* among 2,572 PAH cases. Participants were heterozygous for the indicated variants.

\begin{tabular}{|c|c|c|c|c|c|c|c|c|c|c|c|}
\hline $\begin{array}{l}\text { Participant } \\
\text { ID }\end{array}$ & Gender & $\begin{array}{c}\text { Age at } \\
\text { dx (y) }\end{array}$ & $\begin{array}{c}\text { PAH } \\
\text { subclass }\end{array}$ & Ancestry & Gene $^{\star *}$ & $\begin{array}{c}\text { Nucleotide } \\
\text { change }\end{array}$ & $\begin{array}{l}\text { Amino acid } \\
\text { change }\end{array}$ & $\begin{array}{c}\text { Variant } \\
\text { type }\end{array}$ & $\begin{array}{c}\text { MAF } \\
\text { (ExAC) }\end{array}$ & $\begin{array}{l}\text { CADD } \\
\text { score }\end{array}$ & $\begin{array}{l}\text { Revel } \\
\text { score }\end{array}$ \\
\hline 08-022 & $\mathrm{F}$ & 60 & $\mathrm{IPAH}$ & EUR & $K L K 1$ & c. $46+1 \mathrm{G}>\mathrm{T}$ & p. $(=)$ & splicing & . & 24 & . \\
\hline $10-096$ & $\mathrm{~F}$ & 68 & IPAH & EUR & $K L K 1$ & c.60dup & p.lle21Aspfs*12 & frameshift & 4.29E-05 & . & . \\
\hline $28-049$ & $\mathrm{~F}$ & 36 & APAH-CHD & EUR & $K L K 1$ & c.60dup & p.lle21Aspfs*12 & frameshift & 4.29E-05 & . & . \\
\hline $06-058$ & $M$ & 13 & $\mathrm{IPAH}$ & EUR & $K L K 1$ & c. $70 \mathrm{C}>\mathrm{T}$ & p.Arg24Trp & D-Mis & 8.47E-06 & 26 & 0.56 \\
\hline $13-002$ & $\mathrm{~F}$ & 71 & $\mathrm{IPAH}$ & EUR & $K L K 1$ & c. $.70 \mathrm{C}>\mathrm{T}$ & p.Arg24Trp & D-Mis & 8.47E-06 & 26 & 0.56 \\
\hline 06-007 & M & 26 & IPAH & EUR & $K L K 1$ & c. $113 \mathrm{G}>\mathrm{A}$ & p.Trp38* & stopgain & 8.30E-06 & 35 & . \\
\hline $12-061$ & $\mathrm{~F}$ & 51 & $\mathrm{IPAH}$ & EUR & $K L K 1$ & c. $469 \mathrm{G}>\mathrm{A}$ & p.Gly157Ser & D-Mis & 9.36E-05 & 29 & 0.72 \\
\hline $14-018$ & M & 61 & $\mathrm{IPAH}$ & EUR & $K L K 1$ & c. $469 \mathrm{G}>\mathrm{A}$ & p.Gly157Ser & D-Mis & 9.36E-05 & 29 & 0.72 \\
\hline $17-075$ & $\mathrm{~F}$ & 82 & APAH-CTD & EUR & $K L K 1$ & c. $469 \mathrm{G}>\mathrm{A}$ & p.Gly157Ser & D-Mis & 9.36E-05 & 29 & 0.72 \\
\hline $18-026$ & $\mathrm{~F}$ & 37 & IPAH & EUR & $K L K 1$ & c. $644 \mathrm{G}>\mathrm{A}$ & p.Gly215Glu & D-Mis & . & 30 & 0.85 \\
\hline $19-013$ & $\mathrm{~F}$ & 51 & IPAH & EUR & $K L K 1$ & c. $650 \mathrm{C}>\mathrm{T}$ & p.Pro217Leu & D-Mis & 2.52E-05 & 29 & 0.60 \\
\hline $19-033$ & $\mathrm{~F}$ & 37 & $\mathrm{IPAH}$ & EUR & $K L K 1$ & c. $689 \mathrm{G}>\mathrm{C}$ & p.Trp230Ser & D-Mis & 8.26E-06 & 25 & 0.50 \\
\hline 06-014 & M & 35 & FPAH & EUR & GGCX & c. $137 \mathrm{C}>\mathrm{G}$ & p.Ser46Cys & D-Mis & 5.77E-05 & 23 & 0.70 \\
\hline 04-020 & $\mathrm{F}$ & 36 & $\mathrm{IPAH}$ & EUR & GGCX & c. $G 203 G>C$ & p.Arg68Pro & D-Mis & . & 35 & 0.96 \\
\hline $12-207$ & $\mathrm{~F}$ & 43 & $\mathrm{IPAH}$ & EUR & GGCX & c. $\mathrm{G} 203 \mathrm{G}>\mathrm{C}$ & p.Arg68Pro & D-Mis & . & 35 & 0.96 \\
\hline $32-003$ & M & 81 & $\mathrm{IPAH}$ & EUR & GGCX & c. $248 \mathrm{G}>\mathrm{A}$ & p.Arg83Gln & D-Mis & . & 34 & 0.92 \\
\hline $32-008$ & $\mathrm{~F}$ & 36 & $\mathrm{IPAH}$ & AFR & GGCX & c. $322 \mathrm{C}>\mathrm{T}$ & p.Arg108Cys & D-Mis & 1.65E-05 & 31 & 0.55 \\
\hline $08-013$ & $\mathrm{~F}$ & 66 & APAH-CTD & EUR & GGCX & c.646_647delinsCA & p.Val216Gln & in-frame & . & 31 & $* * *$ \\
\hline $26-036$ & $\mathrm{~F}$ & 52 & $\mathrm{IPAH}$ & EUR & GGCX & c. $722 \mathrm{~T}>\mathrm{C}$ & p.Phe241Ser & D-Mis & . & 33 & 0.94 \\
\hline $30-031$ & $\mathrm{~F}$ & 55 & IPAH & EUR & GGCX & c. $722 \mathrm{~T}>\mathrm{C}$ & p.Phe241Ser & D-Mis & . & 33 & 0.94 \\
\hline 04-029 & $\mathrm{F}$ & 60 & IPAH & EUR & GGCX & c. $734 \mathrm{~T}>\mathrm{A}$ & p.Leu245* & stopgain & . & 40 & . \\
\hline 04-087 & $\mathrm{F}$ & 54 & IPAH & EUR & GGCX & c. $763 \mathrm{G}>\mathrm{A}$ & p.Val255Met & D-Mis & $1.65 \mathrm{E}-05$ & 34 & 0.86 \\
\hline $34-005$ & M & 66 & IPAH & EUR & GGCX & c. $763 \mathrm{G}>\mathrm{A}$ & p.Val255Met & D-Mis & $1.65 \mathrm{E}-05$ & 34 & 0.86 \\
\hline $11-004$ & $\mathrm{~F}$ & 24 & $\mathrm{IPAH}$ & HIS & GGCX & c. $763 \mathrm{G}>\mathrm{A}$ & p.Val255Met & D-Mis & $1.65 \mathrm{E}-05$ & 34 & 0.86 \\
\hline $22-108$ & $\mathrm{~F}$ & 40 & APAH-HIV & AFR & GGCX & c. $899 \mathrm{C}>\mathrm{T}$ & p.Ser300Phe & D-Mis & 2.53E-05 & 28 & 0.82 \\
\hline $28-110$ & $\mathrm{~F}$ & 56 & IPAH & AFR & GGCX & c. $899 \mathrm{C}>\mathrm{T}$ & p.Ser300Phe & D-Mis & $2.53 \mathrm{E}-05$ & 28 & 0.82 \\
\hline 28-096 & $\mathrm{F}$ & 23 & $\mathrm{IPAH}$ & EUR & GGCX & c.938_939del & p.Pro313Argfs $* 33$ & frameshift & $1.00 \mathrm{E}-04$ & . & . \\
\hline $08-046$ & $\mathrm{~F}$ & 53 & APAH-Porto & EUR & GGCX & c. $950 \mathrm{G}>\mathrm{A}$ & p.Arg317Gln & D-Mis & 1.67E-05 & 33 & 0.81 \\
\hline
\end{tabular}




\begin{tabular}{|c|c|c|c|c|c|c|c|c|c|c|c|}
\hline $\begin{array}{c}\text { Participant } \\
\text { ID }\end{array}$ & Gender & $\begin{array}{l}\text { Age at } \\
\mathrm{dx}(\mathrm{y})\end{array}$ & $\begin{array}{c}\text { PAH } \\
\text { subclass }\end{array}$ & Ancestry & Gene $^{\star \star}$ & $\begin{array}{c}\text { Nucleotide } \\
\text { change }\end{array}$ & $\begin{array}{l}\text { Amino acid } \\
\text { change }\end{array}$ & $\begin{array}{c}\text { Variant } \\
\text { type }\end{array}$ & $\begin{array}{c}\text { MAF } \\
\text { (ExAC) }\end{array}$ & $\begin{array}{l}\text { CADD } \\
\text { score }\end{array}$ & $\begin{array}{l}\text { Revel } \\
\text { score }\end{array}$ \\
\hline $12-205$ & $\mathrm{~F}$ & 55 & IPAH & EUR & GGCX & c.1017_1018insT & p.Ser340* & stopgain & 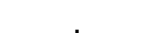 & . & . \\
\hline $15-008$ & $\mathrm{~F}$ & 14 & APAH-CHD & EUR & GGCX & c. $1075 \mathrm{C}>\mathrm{T}$ & p.Arg359Cys & D-Mis & . & 28 & 0.76 \\
\hline $21-037$ & $\mathrm{~F}$ & 45 & APAH-CTD & AFR & GGCX & c. $1128 C>G$ & p.Phe376Leu & D-Mis & . & 27 & 0.85 \\
\hline 06-039 & $\mathrm{F}$ & 28 & IPAH & EUR & GGCX & c. $1224 \mathrm{C}>\mathrm{A}$ & p.His408Gln & D-Mis & 8.24E-06 & 23 & 0.75 \\
\hline $37-004$ & $\mathrm{~F}$ & 48 & $\mathrm{IPAH}$ & EUR & GGCX & c. $1249 \mathrm{G}>\mathrm{A}$ & p.Asp417Asn & D-Mis & $1.65 \mathrm{E}-05$ & 26 & 0.72 \\
\hline $30-034$ & $\mathrm{~F}$ & 49 & APAH-CTD & HIS & GGCX & c. $1304 \mathrm{G}>\mathrm{A}$ & p.Arg435Gln & D-Mis & $8.24 \mathrm{E}-06$ & 29 & 0.67 \\
\hline $14-029$ & M & 48 & $\mathrm{IPAH}$ & EUR & GGCX & c. $1306 \mathrm{C}>\mathrm{T}$ & p.Arg436* & stopgain & 3.30E-05 & 41 & . \\
\hline $37-010$ & $\mathrm{~F}$ & 77 & APAH-CTD & EUR & GGCX & c. $1306 \mathrm{C}>\mathrm{T}$ & p.Arg436* & stopgain & 3.30E-05 & 41 & . \\
\hline $11-090$ & $\mathrm{~F}$ & 47 & APAH & AFR & GGCX & c. $1465 \mathrm{G}>\mathrm{A}$ & p.Val489Met & D-Mis & 2.47E-05 & 26 & 0.68 \\
\hline 05-013 & $\mathrm{M}$ & 63 & APAH-Porto & HIS & GGCX & c. $1480 T>G$ & p.Ser494Ala & D-Mis & . & 26 & 0.84 \\
\hline $28-033$ & $\mathrm{~F}$ & 51 & $\mathrm{IPAH}$ & EUR & GGCX & c. $1758 C>G$ & p.Tyr586* & stopgain & . & 45 & . \\
\hline $17-033$ & $\mathrm{~F}$ & 74 & APAH-CTD & AFR & GGCX & c. $1772 \mathrm{C}>\mathrm{T}$ & p.Thr591Met & D-Mis & 3.30E-05 & 29 & 0.83 \\
\hline
\end{tabular}

${ }^{*}$ Rare, deleterious variants defined as gnomAD AF $\leq 1.00 E-04$ and REVEL $>0.5$.

${ }^{* *}$ KLK1 transcript NM_002257.3 and GGCX transcript NM_000821.6.

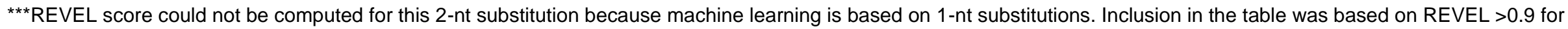
single nt substitution and PROVEAN=deleterious for 2-nt substitution. 
Table 3. Clinical phenotypes of $K L K 1$ and GGCX variant carriers at PAH diagnosis, and compared to mean phenotypes of $B M P R 2$ variant carriers.

\begin{tabular}{|c|c|c|c|c|c|c|c|c|c|c|}
\hline Participant ID & Gender & $\begin{array}{c}\text { PAH } \\
\text { subclass }\end{array}$ & Gene & $\begin{array}{l}\text { Age at } \\
\text { dx (y) }\end{array}$ & $\begin{array}{c}\text { MPAP } \\
(\mathrm{mmHg})\end{array}$ & $\begin{array}{c}\text { MPCW } \\
(\mathrm{mmHg})\end{array}$ & $\begin{array}{c}\text { CO, Fick } \\
\text { (L/min) }\end{array}$ & $\begin{array}{c}\text { PVR } \\
\text { (Woods } \\
\text { units) }\end{array}$ & $\begin{array}{c}\text { MAP } \\
(\mathrm{mmHg})\end{array}$ & $\begin{array}{l}\text { MAP: } \\
\text { MPAP }\end{array}$ \\
\hline 08-022 & $\mathrm{F}$ & IPAH & $K L K 1$ & 60 & 55 & 7 & 2.6 & 18.46 & 98 & 1.78 \\
\hline $10-096$ & $F$ & IPAH & $K L K 1$ & 68 & 46 & 9 & 3.95 & 9.37 & NA & NA \\
\hline $28-049$ & $\mathrm{~F}$ & APAH-CHD & $K L K 1$ & 36 & 61 & 5 & 3.77 & 14.85 & 82 & 1.34 \\
\hline 06-058 & $M$ & IPAH & $K L K 1$ & 13 & 38 & 8 & 8.2 & 3.66 & 92 & 2.42 \\
\hline $13-002$ & $\mathrm{~F}$ & $\mathrm{IPAH}$ & $K L K 1$ & 71 & 44 & 9 & 3.7 & 9.46 & NA & NA \\
\hline $06-007$ & $M$ & IPAH & $K L K 1$ & 26 & 41 & 11 & 5.8 & 5.17 & 97 & 2.37 \\
\hline $12-061$ & $F$ & IPAH & $K L K 1$ & 51 & 53 & 13 & NA & NA & 106 & 2.00 \\
\hline $14-018$ & $\mathrm{M}$ & IPAH & $K L K 1$ & 61 & 37 & 6 & 4.38 & 7.08 & 98 & 2.65 \\
\hline $17-075$ & $F$ & APAH-CTD & $K L K 1$ & 82 & 27 & 7 & 5.23 & 3.82 & NA & NA \\
\hline $18-026$ & $\mathrm{~F}$ & IPAH & $K L K 1$ & 37 & 73 & 15 & NA & NA & NA & NA \\
\hline $19-013$ & $\mathrm{~F}$ & IPAH & $K L K 1$ & 51 & 42 & 13 & 3.6 & 8.06 & 112 & 2.67 \\
\hline $19-033$ & $\mathrm{~F}$ & IPAH & $K L K 1$ & 37 & 34 & 8 & 5.53 & 4.70 & 93 & 2.74 \\
\hline Mean $\pm \mathrm{SD}, K L K 1$ & & & & $49 \pm 20$ & $46 \pm 13$ & $9 \pm 3$ & $4.7 \pm 1.6$ & $8.5 \pm 4.9$ & $97 \pm 9$ & $2.3 \pm 0.5$ \\
\hline $\mathrm{n}, K L K 1$ & & & & 12 & 12 & 12 & 10 & 10 & 8 & 8 \\
\hline Mean $\pm \mathrm{SD}$, BMPR2 & & & & $38 \pm 15$ & $59 \pm 12$ & $10 \pm 4$ & $3.7 \pm 1.3$ & $15.3 \pm 7.3$ & $90 \pm 17$ & $1.6 \pm 0.4$ \\
\hline $\mathrm{n}$, BMPR2 & & & & 181 & 175 & 172 & 123 & 120 & 114 & 114 \\
\hline $\mathrm{p}$-value, $K L K 1$ vs $B M P R 2$ & & & & 0.014 & 0.0007 & NS & 0.02 & 0.004 & NS & $<0.0001$ \\
\hline 06-014 & $M$ & FPAH & GGCX & 35 & 56 & 7 & 2.2 & 22.27 & 103 & 1.84 \\
\hline $04-020$ & $\mathrm{~F}$ & IPAH & GGCX & 36 & 78 & 8 & 2.6 & 26.92 & 71 & 0.91 \\
\hline $12-207$ & $\mathrm{~F}$ & IPAH & GGCX & 43 & 68 & 7 & 2.63 & 23.19 & NA & NA \\
\hline $32-003$ & M & IPAH & GGCX & 81 & 31 & 4 & 4.51 & 5.99 & NA & NA \\
\hline $32-008$ & $\mathrm{~F}$ & IPAH & GGCX & 36 & 49 & 15 & 6.13 & 5.55 & 87 & 1.78 \\
\hline $08-013$ & $\mathrm{~F}$ & APAH-CTD & GGCX & 66 & 40 & 9 & 5.8 & 5.34 & 120 & 3.00 \\
\hline $26-036$ & $\mathrm{~F}$ & $\mathrm{IPAH}$ & GGCX & 52 & 70 & 9 & NA & NA & 86 & 1.23 \\
\hline $30-031$ & $\mathrm{~F}$ & IPAH & GGCX & 55 & 56 & 15 & NA & NA & 121 & 2.16 \\
\hline 04-029 & $\mathrm{F}$ & IPAH & GGCX & 60 & 51 & 8 & 5.53 & 7.78 & NA & NA \\
\hline 04-087 & $\mathrm{F}$ & IPAH & GGCX & 54 & 40 & 14 & 5.64 & 4.61 & 115 & 2.88 \\
\hline
\end{tabular}




\begin{tabular}{|c|c|c|c|c|c|c|c|c|c|c|}
\hline Participant ID & Gender & $\begin{array}{c}\text { PAH } \\
\text { subclass }\end{array}$ & Gene & $\begin{array}{l}\text { Age at } \\
\text { dx (y) }\end{array}$ & $\begin{array}{c}\text { MPAP } \\
(\mathrm{mmHg})\end{array}$ & $\begin{array}{c}\text { MPCW } \\
(\mathrm{mmHg})\end{array}$ & $\begin{array}{c}\text { CO, Fick } \\
\text { (L/min) }\end{array}$ & $\begin{array}{c}\text { PVR } \\
\text { (Woods } \\
\text { units) }\end{array}$ & $\begin{array}{c}\text { MAP } \\
(\mathrm{mmHg})\end{array}$ & $\begin{array}{l}\text { MAP: } \\
\text { MPAP }\end{array}$ \\
\hline 34-005 & $M$ & IPAH & GGCX & 66 & 43 & 14 & 6.85 & 4.23 & 83 & 1.93 \\
\hline $11-004$ & $\mathrm{~F}$ & IPAH & GGCX & 24 & 77 & 11 & NA & NA & NA & NA \\
\hline $22-108$ & $\mathrm{~F}$ & APAH-HIV & GGCX & 40 & 78 & 13 & 5.7 & 11.40 & 94 & 1.21 \\
\hline $28-110$ & $\mathrm{~F}$ & IPAH & GGCX & 56 & 78 & NA & 3.6 & NA & 85 & 1.09 \\
\hline $28-096$ & $\mathrm{~F}$ & IPAH & GGCX & 23 & 65 & 7 & 4.8 & 12.08 & NA & NA \\
\hline 08-046 & $\mathrm{F}$ & APAH-Porto & GGCX & 53 & 44 & 10 & 6.23 & 5.46 & 88 & 2.00 \\
\hline $12-205$ & $\mathrm{~F}$ & IPAH & GGCX & 55 & 52 & 8 & NA & NA & NA & NA \\
\hline $15-008$ & $\mathrm{~F}$ & APAH-CHD & GGCX & 14 & 60 & 12 & 2.5 & 19.20 & 62 & 1.03 \\
\hline 21-037 & $\mathrm{F}$ & APAH-CTD & GGCX & 45 & 31 & 12 & 5.26 & 3.61 & NA & NA \\
\hline 06-039 & $\mathrm{F}$ & IPAH & GGCX & 28 & 48 & 11 & 4.6 & 8.04 & 81 & 1.69 \\
\hline 37-004 & $\mathrm{F}$ & IPAH & GGCX & 48 & 49 & 18 & 3.6 & 8.61 & 67 & 1.37 \\
\hline $30-034$ & $\mathrm{~F}$ & APAH-CTD & GGCX & 49 & 38 & 17 & NA & NA & NA & NA \\
\hline 14-029 & $M$ & IPAH & GGCX & 48 & 50 & 14 & NA & NA & NA & NA \\
\hline $37-010$ & $\mathrm{~F}$ & APAH-CTD & GGCX & 77 & 28 & 6 & NA & NA & 74 & 2.64 \\
\hline $11-090$ & $\mathrm{~F}$ & $\mathrm{APAH}$ & GGCX & 47 & NA & NA & NA & NA & NA & NA \\
\hline $05-013$ & $M$ & APAH-Porto & GGCX & 63 & 33 & 6 & 6.31 & 4.28 & 119 & 3.61 \\
\hline $28-033$ & $\mathrm{~F}$ & IPAH & GGCX & 51 & 61 & NA & 3.6 & NA & 85 & 1.39 \\
\hline $17-033$ & $\mathrm{~F}$ & APAH-CTD & GGCX & 74 & 45 & 7 & 3.69 & 10.30 & 88 & 1.96 \\
\hline Mean \pm SD, GGCX & & & & $49 \pm 16$ & $53 \pm 15$ & $10 \pm 4$ & $4.6 \pm 1.4$ & $10.5 \pm 7.4$ & $91 \pm 18$ & $1.9 \pm 0.8$ \\
\hline $\mathrm{n}, \mathrm{GGCX}$ & & & & 28 & 27 & 25 & 20 & 18 & 18 & 18 \\
\hline Mean $\pm \mathrm{SD}$, BMPR2 & & & & $38 \pm 15$ & $59 \pm 12$ & $10 \pm 4$ & $3.7 \pm 1.3$ & $15.3 \pm 7.3$ & $90 \pm 17$ & $1.6 \pm 0.4$ \\
\hline $\mathrm{n}$, BMPR2 & & & & 181 & 175 & 172 & 123 & 120 & 114 & 114 \\
\hline $\mathrm{p}$-value, $G G C X$ vs $B M P R 2$ & & & & $<0.0001$ & 0.02 & NS & 0.004 & 0.01 & NS & 0.007 \\
\hline
\end{tabular}

Abbreviations: Age at dx, participant age at diagnosis/right heart catheterization; MPAP, mean pulmonary arterial pressure; MPCW, mean pulmonary capillary pressure; CO, cardiac output by the Frick method; PVR, pulmonary vascular resistance; MAP, mean arterial pressure. 


$$
5
$$


Figure 2

a)

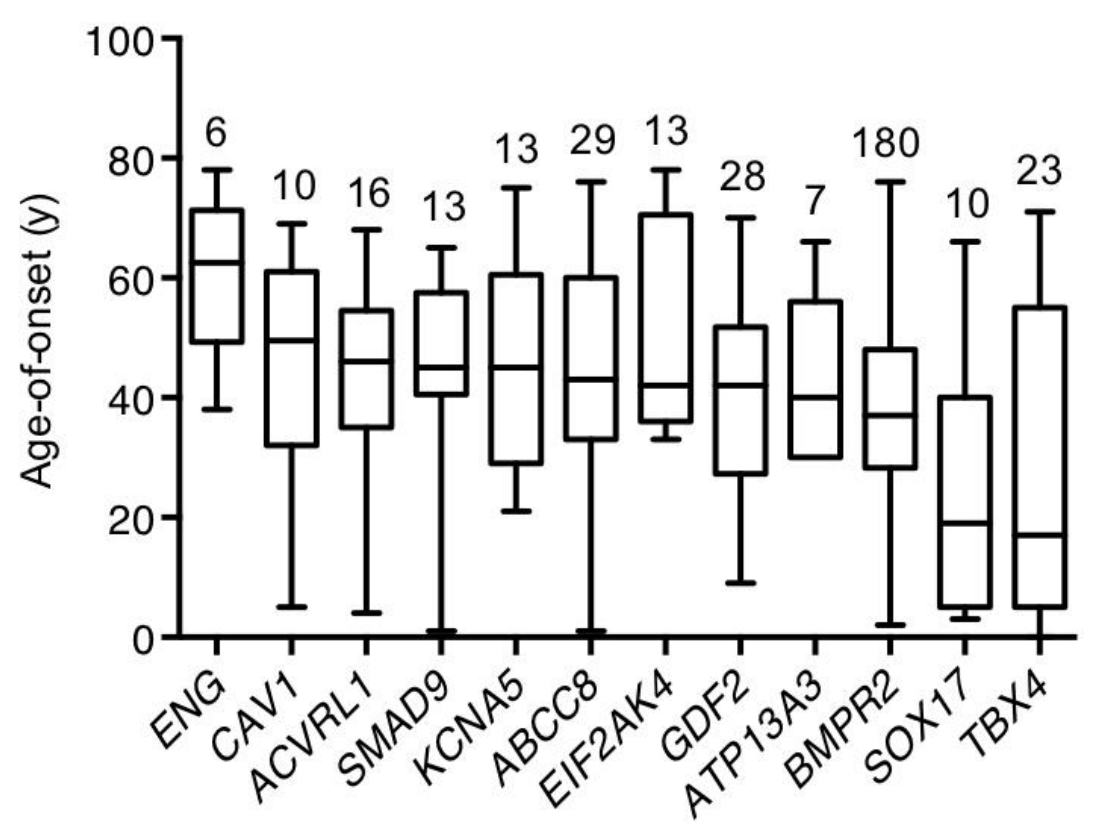

b)
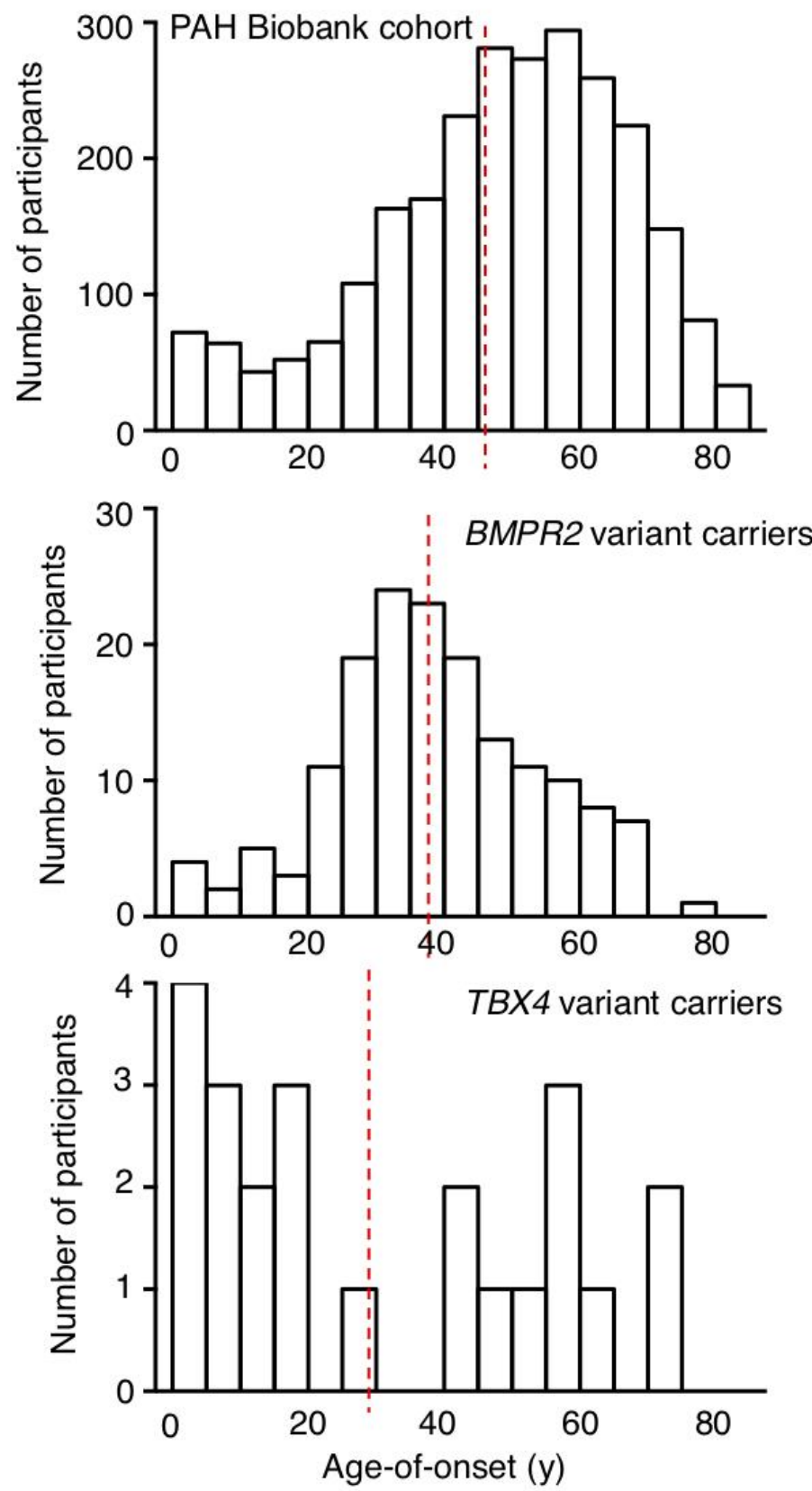
Figure 3

a)

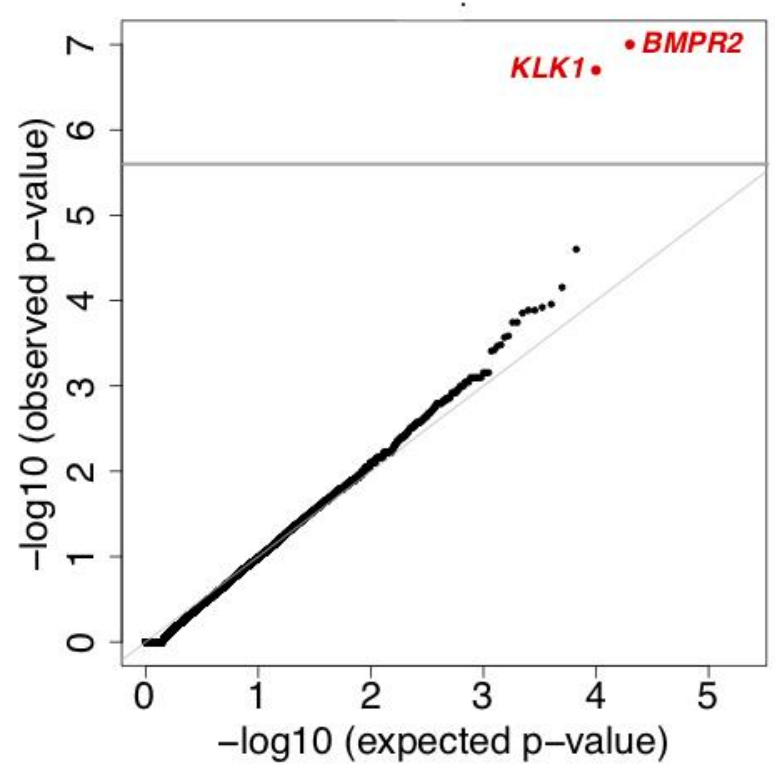

b)

\begin{tabular}{|l|l|c|c|}
\hline \multicolumn{1}{|c|}{ Gene } & \multicolumn{1}{|c|}{ Gene name } & p-value & FDR \\
\hline BMPR2 & Bone morphogenetic protein receptor type 2 & $\mathbf{1 . 0 0 E}-07$ & $\mathbf{0 . 0 0 2}$ \\
\hline KLK1 & Tissue kallikrein 1 & $\mathbf{2 . 0 0 \mathrm { E } - 0 7}$ & $\mathbf{0 . 0 0 2}$ \\
\hline ACVRL1 & Activin A receptor type II-like 1 & $2.50 \mathrm{E}-05$ & 0.15 \\
\hline GDF2 & Growth differentiation factor 2 & $7.00 \mathrm{E}-05$ & 0.28 \\
\hline TTC37 & Tetratricopeptide repeat domain 37 & $1.10 \mathrm{E}-04$ & 0.28 \\
\hline PXYLP1 & 2-Phosphoxylose phosphatase 1 & $1.20 \mathrm{E}-04$ & 0.28 \\
\hline OR5212 & Olfactory receptor family 52 subfamily 1 member 2 & $1.30 \mathrm{E}-04$ & 0.28 \\
\hline PLPP1 & Phosphatidic acid phosphatase type 2A & $1.30 \mathrm{E}-04$ & 0.28 \\
\hline PODXL & Podocalyxin like & $1.40 \mathrm{E}-04$ & 0.28 \\
\hline FBXO10 & F-box protein 10 & $1.80 \mathrm{E}-04$ & 0.29 \\
\hline ZNF513 & Zinc finger protein 513 & $1.80 \mathrm{E}-04$ & 0.29 \\
\hline GGCX & Gamma-glutamyl carboxylase & $2.60 \mathrm{E}-04$ & 0.37 \\
\hline$D E F B 134$ & Defensin beta 134 & $2.70 \mathrm{E}-04$ & 0.37 \\
\hline QSOX2 & Quiescin 6 sulfhydryl oxidase 2 & $3.30 \mathrm{E}-04$ & 0.41 \\
\hline ZMYND12 & Zinc finger MYND-type containing 12 & $3.40 \mathrm{E}-04$ & 0.41 \\
\hline LAMB1 & Laminin subunit beta 1 & $3.80 \mathrm{E}-04$ & 0.41 \\
\hline OCA2 & OCA2 melanosomal transmembrane protein & $3.90 \mathrm{E}-04$ & 0.41 \\
\hline CCDC96 & Coiled coil domain containing 96 & $7.00 \mathrm{E}-04$ & 0.55 \\
\hline SGSM2 & Small G-protein signaling modulator 2 & $7.00 \mathrm{E}-04$ & 0.55 \\
\hline NMRK2 & Nicotinamide riboside kinase 2 & $7.00 \mathrm{E}-04$ & 0.55 \\
\hline ADRB2 & Adrenoceptor beta 2 & $8.00 \mathrm{E}-04$ & 0.55 \\
\hline EVX1 & Even-skipped homeobox homolog 1 & $8.00 \mathrm{E}-04$ & 0.55 \\
\hline GNAS & GNAS complex locus & $8.00 \mathrm{E}-04$ & 0.55 \\
\hline SIDT2 & SID1 transmembrane family member 2 & $8.00 \mathrm{E}-04$ & 0.55 \\
\hline TRIM35 & Tripartite motif containing 35 & $8.00 \mathrm{E}-04$ & 0.55 \\
\hline TTC25 & Tetratricopeptide repeat domain 25 & $8.00 \mathrm{E}-04$ & 0.55 \\
\hline DPAGT1 & Dolichyl-phosphate N- & $9.00 \mathrm{E}-04$ & 0.55 \\
\hline acetylglucosaminephosphotransferase 1 & & \\
\hline
\end{tabular}


Figure 4

a)

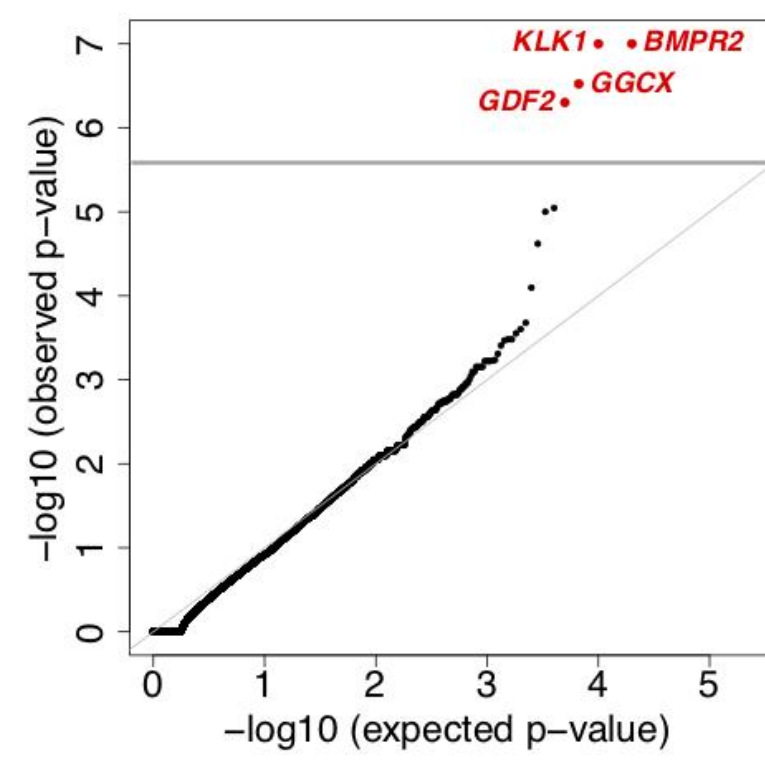

b)

\begin{tabular}{|l|l|c|c|}
\hline \multicolumn{1}{|c|}{ Gene } & \multicolumn{1}{|c|}{ Gene name } & p-value & FDR \\
\hline BMPR2 & Bone morphogenetic protein receptor type 2 & $\mathbf{1 . 0 0 E}-07$ & $\mathbf{9 . 0 0 E}-04$ \\
\hline KLK1 & Tissue kallikrein 1 & $\mathbf{1 . 0 0 E}-07$ & $\mathbf{9 . 0 0 E}-04$ \\
\hline GGCX & Gamma-glutamyl carboxylase & $\mathbf{3 . 0 0 E}-07$ & $\mathbf{0 . 0 0 2}$ \\
\hline GDF2 & Growth differentiation factor 2 & $\mathbf{5 . 0 0 E}-07$ & $\mathbf{0 . 0 0 2}$ \\
\hline ZNF513 & Zinc finger protein 513 & $9.00 \mathrm{E}-06$ & 0.03 \\
\hline ASPHD2 & Aspartate beta hydroxylase domain containing 2 & $1.00 \mathrm{E}-05$ & 0.03 \\
\hline TBX4 & T-box 4 & $2.40 \mathrm{E}-05$ & 0.06 \\
\hline SGSM2 & Small G-protein signaling modulator 2 & $8.00 \mathrm{E}-05$ & 0.18 \\
\hline TCAP & Titin cap & $2.10 \mathrm{E}-04$ & 0.42 \\
\hline RIMKLB & Ribosomal modification protein RimK like family member B & $2.50 \mathrm{E}-04$ & 0.44 \\
\hline KLF4 & Kruppel-like factor 4 & $2.80 \mathrm{E}-04$ & 0.44 \\
\hline LAMB1 & Laminin subunit beta 1 & $3.30 \mathrm{E}-04$ & 0.44 \\
\hline TET2 & Tet methylcytosine dioxygenase 2 & $3.30 \mathrm{E}-04$ & 0.44 \\
\hline DPAGT1 & Dolichyl-phosphate N-acetylglucosaminephosphotransferase 1 & $3.40 \mathrm{E}-04$ & 0.44 \\
\hline EVX1 & Even-skipped homeobox homolog 1 & $3.90 \mathrm{E}-04$ & 0.47 \\
\hline TUBG2 & Tubulin gamma 2 & $4.90 \mathrm{E}-04$ & 0.50 \\
\hline ACR & Acrosin & $5.80 \mathrm{E}-04$ & 0.50 \\
\hline MARS & Methionyl t-RNA synthetase & $5.90 \mathrm{E}-04$ & 0.50 \\
\hline INPP5E & Inositol polyphosphate-5-phosphatase E & $6.00 \mathrm{E}-04$ & 0.50 \\
\hline NKX2-8 & NK2 homeobox 8 & $6.00 \mathrm{E}-04$ & 0.50 \\
\hline TCERG1L & Transcription elongation regulator 1 like & $6.00 \mathrm{E}-04$ & 0.50 \\
\hline OR52I2 & Olfactory receptor family 52 subfamily 1 member 2 & $7.00 \mathrm{E}-04$ & 0.50 \\
\hline PHOX2A & Paired like homeobox 2a & $7.00 \mathrm{E}-04$ & 0.50 \\
\hline TSHZ2 & Teashirt zinc finger homeobox 2 & $7.00 \mathrm{E}-04$ & 0.50 \\
\hline UTP11 & UTP11, small subunit processome component & $7.00 \mathrm{E}-04$ & 0.50 \\
\hline MYO5B & Myosin VB & $8.00 \mathrm{E}-04$ & 0.53 \\
\hline PLIN5 & Perilipin 5 & $8.00 \mathrm{E}-04$ & 0.53 \\
\hline TTC37 & Tetratricopeptide repeat domain 37 & $9.00 \mathrm{E}-04$ & 0.58 \\
\hline
\end{tabular}


Figure 5

a)

\section{KLK1}

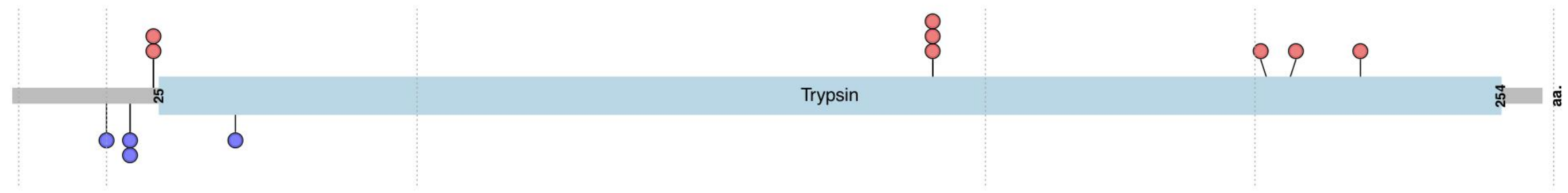

D-Mis $\bigcirc$ LGD

b) GGCX

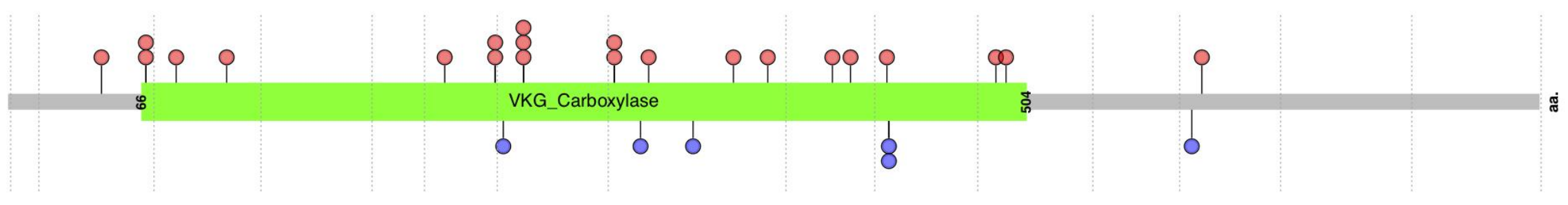

D-Mis LGD 